\title{
Prevention of the post-chemotherapy relapse of tuberculous infection by combined immunotherapy
}

\author{
Simona Buccheri ${ }^{a}$, Rajko Reljic ${ }^{b}, N$ adia Caccamo ${ }^{a}$, Serena Meraviglia ${ }^{a}$, Juraj Ivanyi ${ }^{c}$, \\ Alfredo Salerno ${ }^{a}$, Francesco Dieli ${ }^{a}, *$ \\ ${ }^{a}$ Dipartimento di Biopatologia e Metodologie Biomediche, Università di Palermo, Corso Tukory 211, Palermo, Italy \\ ${ }^{\mathrm{b}}$ Molecular Immunology Group, St. George's Hospital Medical School, London, UK

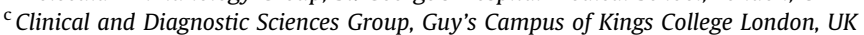

\section{A R T I C L E I N F O}

\section{Article history:}

Received 20 May 2008

Received in revised form 31 July 2008

Accepted 5 September 2008

\section{Keywords:}

Tuberculosis

Cytokines

Antibodies

Immunotherapy

Relapse

\begin{abstract}
S U M M A R Y
We report that a recently developed combined immunotherapy (CIT) has the capacity to prevent a spontaneous relapse of replicating Mycobacterium tuberculosis bacilli in the lungs of BALB/c, C57Bl/6 or $\mathrm{C} 3 \mathrm{H} / \mathrm{HeJ}$ strains of mice, following 4 weeks of non-sterilising treatment with isoniazid and rifampicin. The CIT regimen, represented by recombinant IFN $\gamma$, anti- $\alpha$ crystalline monoclonal IgA antibody and IL- 4 neutralizing polyclonal antibody, reduced the 8-week relapse of viable bacterial counts in the lungs most significantly, when CIT was inoculated during the 5th week post infection, i.e. during the 3rd week of chemotherapy. Although CIT enhanced lung granuloma area, nitric oxide, cytokine and chemokine levels in lung washings significantly, these could not be directly associated with the beneficial effect of CIT on the degree of relapse in the lungs. These results represent a proof-of-principle, that the described CIT, when combined with chemotherapy, could have potential for future development of a shorter regimen of tuberculosis treatment.
\end{abstract}

(c) 2008 Elsevier Ltd. All rights reserved.

\section{Introduction}

Chemotherapy of tuberculosis (TB) can have a very high cure rate; however, poor patient compliance with the protracted regimen in areas with limited resources can be a significant problem, leading to relapse of active disease, transmission of infection and development of drug resistant strains. Attempts to eliminate latent persisters by non-specific (e.g. cytokine) or antigen-specific (e.g. vaccination) immunological agents, ${ }^{1,2}$ i.e. 'immunotherapy as an adjunct to chemotherapy' have been made in a number of experimental models. Using a short regimen of incomplete (non-sterilizing) chemotherapy, muramyl dipeptide was reported to reduce the relapse partially in the lungs, but not in the spleens of mice. ${ }^{3}$ Treatment of TB patients with recombinant IL$2^{4}$ or Mycobacterium vaccae ${ }^{5}$ failed to improve chemotherapy. Vaccination of mice reduced the post-chemotherapy relapse of Mycobacterium tuberculosis (Mtb) infection when using hsp65 $5^{6,7}$ or Ag85A ${ }^{8}$ DNA plasmids, or a detoxified Mtb extract in liposomes (RUTI), ${ }^{9}$ although negative results were reported by others. ${ }^{10,11}$ Passive inoculation of a polyclonal antiserum against an Mtb

\footnotetext{
* Corresponding author. Tel.: +39 091 6555916; fax: +39 0916555901. E-mail address: dieli@unipa.it (F. Dieli).
}

extract reduced the post-chemotherapy relapse in SCID mice. ${ }^{12}$ Considering the advances made and the importance of the potential clinical aims, further research on the concept of immunotherapy, as an adjunct to chemotherapy of TB, has been recommended. ${ }^{13,14}$

This study has been initiated under the direct influence of our preceding experiments which showed, that (i) passive vaccination with a mouse IgA monoclonal antibody (mAb) against the $\alpha$-crystallin (Acr) antigen of Mtb together with IFN $\gamma$ reduced the lung infection and pathology in BALB/c mice ${ }^{15}$ and (ii) combining this regimen with the inoculation of IL-4 neutralizing antibody was even more protective. ${ }^{16}$ The combined immunotherapy regimen composed of IFN $\gamma+\operatorname{IgA}+$ anti-IL-4 was evaluated in this study for its capacity to reduce the spontaneous relapse of active tuberculous infection following short-term (incomplete) chemotherapy.

\section{Methods}

\subsection{Mice and infection}

BALB/c and C57Bl/6 mice (OLAC Ltd. through Nossan, Correzzana, Italy) and $\mathrm{C} 3 \mathrm{H} / \mathrm{HeJ}$ mice (Jackson Laboratories USA) were kept under specific pathogen-free conditions. Six mice per group (matched for sex and age between 8 and 10 weeks) were infected 
(under light anaesthesia) i.n. with $2.5 \times 10^{5}$ colony-forming units (CFUs) of mid-log-phase Mtb H37Rv in $0.02 \mathrm{ml}$ of saline.

\subsection{Chemotherapy}

The 'short duration' chemotherapy entailed the delivery of $25 \mathrm{mg}$ of isoniazid (INH) and $10 \mathrm{mg}$ of rifampicin (R) (Sigma) per $100 \mathrm{ml}$ of drinking water from day 14 post infection, for a period of 4 weeks (i.e. 2 nd to 6 th week). This regimen is known to abrogate almost completely CFU counts in the lungs and spleen, followed by a rapid spontaneous relapse ('regrowth') of tubercle bacilli within a period of 2-4 weeks. ${ }^{3}$

\subsection{Combined immunotherapy (CIT) agents and regimen}

Mouse IFN $\gamma$ (Serotech, Oxford, UK) $1 \mu \mathrm{g}$ (100,000 U)/mouse, intranasally (i.n.) goat polyclonal anti-mouse IL-4 antibody (R\&D Systems, cat. no. AF-404-NA), $500 \mu \mathrm{g}$ per mouse intravenously (i.v.); TBA61, affinity purified mouse anti-Acr $\operatorname{IgA} \mathrm{mAb}(1.5 \mathrm{mg} / \mathrm{ml}$, antigen-binding titre 100,000$), 37 \mu$ in $25 \mu$ l per mouse i.n. ${ }^{17}$ The time schedule of the CIT is shown schematically in Figure 1. Inoculations during the $3 \mathrm{rd}$, 5th or 7th week and re-inoculation on the 9th week post-infection were given on the following days of the respective weeks: day 1, IFN $\gamma$ i.n.; day 2, anti-IL4 i.v.; days 3 and 7, IFN $\gamma$ and TBA61 i.n.

\subsection{CFU assay}

Lungs and spleens harvested at different time intervals post infection were homogenised in $5 \mathrm{ml}$ of sterile water and $10 \mu \mathrm{l}$ aliquots of the serially diluted homogenates were plated on duplicate Middlebrook 7H11 (Difco, cat. no. 283810) agar plates. CFUs were counted after $2-4$ weeks of incubation at $37^{\circ} \mathrm{C}$.

\subsection{Nitrite, cytokine and chemokine assays}

Bronchoalveolar lavage obtained by flushing $2 \mathrm{ml}$ of PBS into the lungs of killed mice was used to determine the concentration of nitrite, using the Griess reagent (Sigma). ELISA kits (R \& D Systems) were used to test cytokine (TNF- $\alpha$, IL-1 $\beta$ ) and chemokine (CCL3/MIP-1 $\alpha$, CCL4/ MIP-1 $\beta$ ) levels according to the manufacturer's recommendations.

\subsection{Histology and morphometry}

Lungs were fixed in $10 \%$ buffered formalin and embedded in paraffin. Haematoxylin-eosin stained sections $(5-6 \mu \mathrm{m})$ were photographed $(\times 6)$ using a Stereoscopic Zoom SMZ800 microscope (Nikon, Tokyo, Japan) and a Coolpix 990 digital camera (Nikon). Software programs Scion Image (Scion Corporation, Frederick, MD, USA) and Photoshop 5.0 (Adobe Systems Incorporated, San José, CA, USA) were used to determine the area with granuloma lesions. ${ }^{18}$

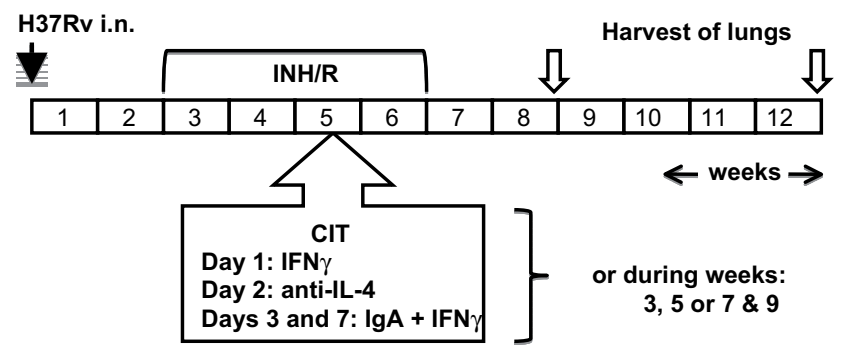

Figure 1. Schematic representation of the experimental design for analysing the effects of the combined immunotherapy (CIT) on the relapse of Mtb infection following INH/R chemotherapy.
The relative granuloma involving areas were calculated from two independents measurements.

\subsection{Statistical analysis}

The significance of differences in CFU counts between groups was determined by one-way analysis of variance (ANOVA) on the $\log _{10}$ values with Scheffe tests for the post-ANOVA individual comparisons. When calculating group mean values, samples without detectable colonies were assigned a value of 50 CFU, representing the threshold of detection sensitivity. Student's $t$ test was used for the analysis of granuloma, NO, cytokine and chemokine values in the lungs.

\section{Results}

\subsection{The effect of CIT timing}

The results (Figure 2A, Table 1) showed that mean CFU counts in the lungs at the end of 4 weeks of INH/R treatment were below detection in 4 out of 6 mice ( 85 CFUs). A pronounced spontaneous relapse of infection was demonstrable on the 8th week post infection (11,220 CFUs) in all 6 mice in the group. We investigated the efficacy of the CIT, when given during the 3rd, 5th or 7th week post infection to prevent this relapse. The results showed that CIT given during the 5th week, reduced the mean CFU values of lung infection more effectively (78 CFUs, $p=0.001$; CFUs undetectable in 5/6 mice) than CIT given either during the 3rd week (562 CFUs, $p=0.006$ ) or the 7 th week (1995 CFUs, $p=0.393$ ). Nevertheless,
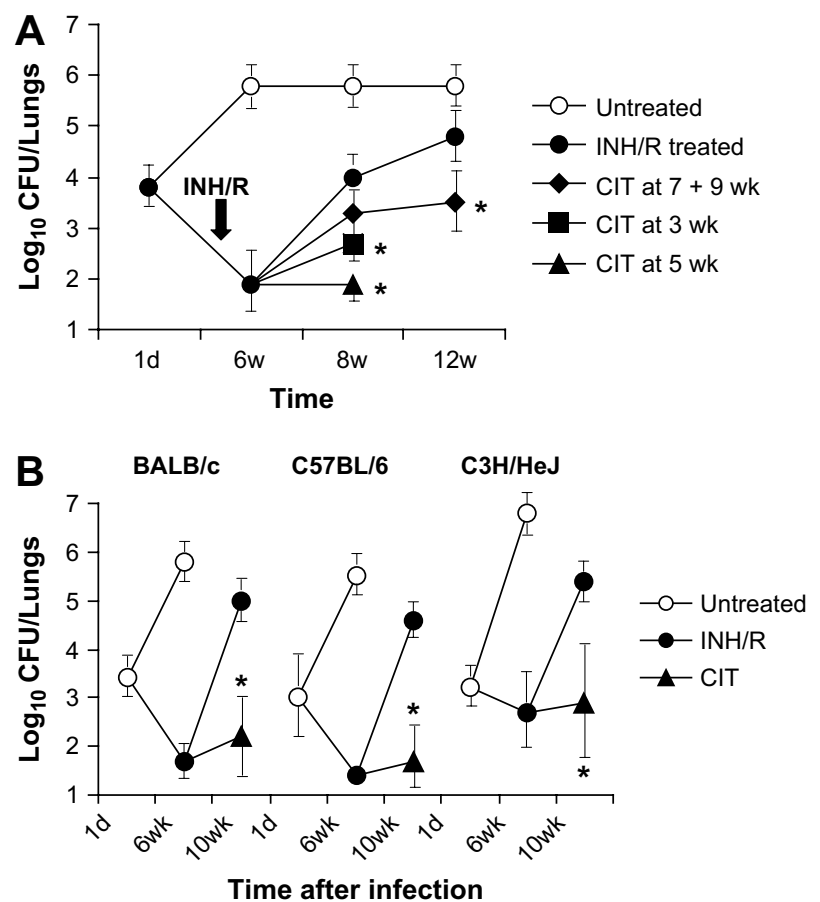

Figure 2. Influence of CIT on the post-chemotherapy relapse in the lungs of Mtb infected mice. (A) The influence of CIT timing. Isoniazid and rifampicin (INH/R arrow) were in the drinking water from the 2nd to 6th week after i.n. H37Rv infection and CIT was given at different weeks (wk) indicated in the figure (dosage: see Methods section). Symbols: mean $\log _{10}$ CFU values, vertical bars $=\mathrm{SD}$; * indicates statistically significant difference when compared with the INH/R only treated group $(p<0.05)$. (B) The effect of CIT in three different strains of mice. BALB/c, $\mathrm{C} 57 \mathrm{BL} / 6$ and $\mathrm{C} 3 \mathrm{H} / \mathrm{HeJ}$ mice received INH/R on weeks 2-6 and CIT during week 5 after i.n. H37Rv infection. Mean $\log _{10}$ CFU and SD (vertical bars) values from lungs harvested 10 weeks after infection. *Significant $(p<0.005)$ difference, when comparing CIT treated with $\mathrm{INH} / \mathrm{R}$ only treated groups. 
Table 1

Levels of organ infection in individual mice.

\begin{tabular}{|c|c|c|c|c|c|c|}
\hline \multirow[t]{2}{*}{ Mouse strain } & \multirow[t]{2}{*}{ INH/R at 2-6 weeks } & \multirow[t]{2}{*}{ CIT at the week: } & \multicolumn{4}{|c|}{ Number of mice with $<50 / 50-500 />500$ CFUs per lung at following weeks after H37Rv infection: } \\
\hline & & & 6 weeks & 8 weeks & 10 weeks & 12 weeks \\
\hline \multirow[t]{6}{*}{$\overline{\mathrm{BALB} / \mathrm{c}}$} & - & - & $0 / 0 / 6$ & $0 / 0 / 6$ & & $0 / 0 / 6$ \\
\hline & + & - & $4 / 2 / 0$ & $0 / 0 / 6$ & & $0 / 0 / 6$ \\
\hline & + & 3 & & $1 / 2 / 3$ & & \\
\hline & + & 5 & & $5 / 1 / 0$ & & \\
\hline & + & 7 & & $0 / 2 / 4$ & & \\
\hline & + & $7+9$ & & & & $0 / 0 / 6$ \\
\hline \multirow[t]{3}{*}{$\mathrm{BALB} / \mathrm{c}$} & - & - & $0 / 0 / 6$ & & & \\
\hline & + & - & $5 / 1 / 0$ & & $0 / 0 / 6$ & \\
\hline & + & 5 & & & $4 / 0 / 2$ & \\
\hline \multirow[t]{3}{*}{$\mathrm{C} 57 \mathrm{Bl} / 6$} & - & - & $0 / 0 / 6$ & & & \\
\hline & + & - & $6 / 0 / 0$ & & $0 / 0 / 6$ & \\
\hline & + & 5 & & & $4 / 0 / 1$ & \\
\hline \multirow[t]{3}{*}{$\mathrm{C} 3 \mathrm{H} / \mathrm{HeJ}$} & - & - & $0 / 0 / 6$ & & & \\
\hline & + & - & $2 / 0 / 4$ & & $0 / 0 / 6$ & \\
\hline & + & 5 & & & $2 / 0 / 4$ & \\
\hline
\end{tabular}

See Figure 2 for mean CFU counts and experimental details.

CIT given on both the 7th and 9th week reduced the mean lung CFUs (3020, $p=0.003$ ) significantly at 12 weeks after infection. These results showed that the timing of CIT application plays a crucial role for its capacity to reduce the relapse of replicating tubercle bacilli in the lungs, following chemotherapy.

\subsection{The effect of CIT in different strains of mice}

At the end of $\mathrm{INH} / \mathrm{R}$ treatment (i.e. at 6 weeks), on the $\mathrm{C} 57 \mathrm{Bl} / 6$ and BALB/c mice (both strains genetically resistant to pulmonary disease $\left.{ }^{19}\right)$, lung CFUs were undetectable in 5 or 6 mice out of the 6 per group (Table 1). A pronounced spontaneous relapse in all mice followed at 10 weeks (Table 1, Figure 2B). The CIT regimen was inoculated during the 5th week after infection, because that was found to be the most effective timing in the preceding experiment. This CIT regimen prevented any relapse at 10 weeks in the lungs of 4 mice out of the 6 or 5 per group. In the genetically susceptible $\mathrm{C} 3 \mathrm{H} / \mathrm{HeJ}$ strain ${ }^{19}$ however, at the end of the INH/R treatment, 4 out of 6 mice retained a moderate levels of lung infection (Table 1; mean 617 CFUs). Nevertheless, the strongly relapsed lung infection at 10 weeks was reduced by CIT significantly (from 331,131 to 1513 CFUs; $p=0.001$ ).

\subsection{Analysis of lung mediator levels and granuloma areas}

The lungs harvested at 8 weeks after Mtb infection of BALB/c mice (see their CFU counts in Figure 2A) were tested for the size of the granuloma area and for NO, TNF $\alpha$, IL-1 $\beta$, RANTES, CCL3 and CCL4 levels in lung lavage fluids. The levels of these mediators were found to be significantly lower in Mtb infected, INH/R treated mice, than in the untreated Mtb-infected control mice (Table 2). CIT given in the 5 th or 7 th week post infection resulted in a significant $(p<0.01-0.001)$ increase of granuloma, NO, TNF $\alpha$, IL1 $\beta$, RANTES, CCL3 and CCL4 levels when compared with INH/R only treated mice. In contrast, the levels of IL10 and TGF $\beta$ were decreased at the same time. However, CIT given on the 3rd week failed to influence significantly the values of most of these assays.

\section{Discussion}

The CIT employed substantially alleviated the spontaneous relapse, following short-term INH/R chemotherapy in the lungs of Mtb infected mice. The selected time schedule of CIT inoculations significantly influenced its efficacy: the best effect, almost completely preventing the relapse in lung CFUs was obtained, when CIT was administered during the 5th week after Mtb infection, i.e. during the 3rd week of INH/R chemotherapy. The effect of CIT on the relapse of splenic CFUs was also tested, but the results varied between experiments (results not shown). The extent by which the spontaneous post-chemotherapy relapse was prevented has been more profound than the previously reported CIT inhibition of fresh Mtb infection. ${ }^{16}$ This could be due to differences between the persister or replicating target organisms. Furthermore, persisters arising rapidly following chemotherapy are apparently resilient to host $\mathrm{T}$ cell immunity, unlike the dormant organisms generated following acquired host $\mathrm{T}$ cell immunity. ${ }^{20,21}$

$\mathrm{INH} / \mathrm{R}$ treatment alone decreased the extent of granuloma infiltration of the lungs and the levels of most of the tested cytokine and chemokine mediators in the lung lavage. This decrease seems to reflect the bactericidal effect which reduced the CFU counts below the level of detection at 6 weeks. Administration of CIT to INH/R-treated mice paradoxically increased the lung granuloma

Table 2

Influence of CIT on lung granuloma area, NO, cytokine and chemokine levels in lung lavage fluids 8 weeks after H37Rv infection.

\begin{tabular}{|c|c|c|c|c|c|}
\hline \multirow[t]{2}{*}{ Assay } & \multicolumn{5}{|c|}{ Group mean values $\pm S E$} \\
\hline & No treatment & INH/R without CIT & CIT at 3 weeks & CIT at 5 weeks & CIT at 7 weeks \\
\hline Granuloma $\left(\mathrm{mm}^{2}\right)$ & $10 \pm 3$ & $4 \pm 1^{@}$ & $7 \pm 2$ & $13 \pm 5^{*}$ & $16 \pm 4^{*}$ \\
\hline $\mathrm{NO}(\mu \mathrm{M} / \mathrm{ml})$ & $25 \pm 8$ & $12 \pm 5$ & $45 \pm 15$ & $60 \pm 20^{* *}$ & $55 \pm 18^{*}$ \\
\hline $\mathrm{TNF} \alpha(\mathrm{pg} / \mathrm{ml})$ & $310 \pm 80$ & $90 \pm 10^{@}$ & $210 \pm 60$ & $280 \pm 70$ & $320 \pm 40^{*}$ \\
\hline IL- $1 \beta \mathrm{pg} / \mathrm{ml}$ & $830 \pm 145$ & $150 \pm 50^{@}$ & $320 \pm 75$ & $520 \pm 210$ & $710 \pm 150^{*}$ \\
\hline IL-10 (pg/ml) & $190 \pm 40$ & $220 \pm 40$ & $120 \pm 10$ & $85 \pm 15$ & $140 \pm 35$ \\
\hline TGF- $\beta(\mathrm{pg} / \mathrm{ml})$ & $80 \pm 25$ & $310 \pm 90^{@ @ ~}$ & $70 \pm 20^{*}$ & $80 \pm 15^{*}$ & $120 \pm 30$ \\
\hline RANTES (pg/ml) & $1050 \pm 340$ & $170 \pm 35^{@}$ & $650 \pm 160^{*}$ & $840 \pm 90^{* *}$ & $880 \pm 50^{* *}$ \\
\hline CCL3 (pg/ml) & $920 \pm 320$ & $120 \pm 30^{@}$ & $440 \pm 120$ & $620 \pm 180^{* *}$ & $850 \pm 130^{* *}$ \\
\hline CCL4 (pg/ml) & $840 \pm 210$ & $160 \pm 40^{@}$ & $420 \pm 110$ & $660 \pm 70^{*}$ & $710 \pm 120^{*}$ \\
\hline
\end{tabular}

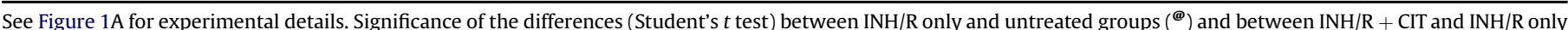
treated groups $\left({ }^{*}\right)$. Two symbols, $p<0.0001$; one symbol $=p<0.01$. 
area and the lung lavage levels of NO and of several of the proinflammatory cytokines and chemokines to values close to those observed in the high CFUs bearing control-infected mice. CIT may have influenced the nature and composition of these granulomas, with a greater influx of inflammatory cells, ${ }^{22,23}$ enabling them to exhibit greater bactericidal action. Alternatively, CIT may have acted by loosening the granuloma shelter, ${ }^{24}$ which in turn may lead to increased drug accessibility. Nevertheless, these aspects seem complex and we cannot draw direct conclusions from our results, when considering that the levels of the pro-inflammatory mediators were increased by CIT which imparted either high (week 5 CIT) or low (week $7 \mathrm{CIT}$ ) protection.

The relative contribution of the three constituents of CIT needs further analysis. Antibody action could rest on its binding specificity for the Acr antigen, which is elevated in stationary phase organisms, ${ }^{25}$ in the lungs of mice ${ }^{26}$ and in response to NO or hypoxic stress ${ }^{27,28}$ and notably in the highly virulent Beijing family of Mtb. ${ }^{29,30}$ IFN $\gamma$ may act by amplifying the protection by $\operatorname{Ig} \mathrm{A}^{17}$ or by stimulating V $\alpha 14^{+} / \mathrm{NK} 1.1$ T cells. ${ }^{31}$ The anti- IL-4 element of the CIT probably reduced the lung lavage levels of the TGF $\beta$ and IL-10 deactivating Th2 cytokines which can aggravate active infection. ${ }^{32}$ The use of the rapid post-chemotherapy relapse model seemed suitable to obtain the proof-of-potency of the combined antibody and cytokine based immunotherapy. While having the advantage of the 3 month test period, rapid re-growth of lung CFUs may be due to mechanisms, possibly different from those involved in the long duration models of relapse.

\section{Acknowledgements}

We thank Mr Ron Wilson, for help with the statistical analysis and Dr S. Balu for reading the manuscript (both from Kings College London).

Funding: University of Palermo, the Italian Ministry for University and Research, The Dunhill Medical Trust, London and The Wellcome Trust London.

\section{Competing Interests: None declared.}

\section{Ethical approval: By the Animal Ethics Committee (Palermo).}

\section{References}

1. Cannetti G. Host factors and chemotherapy of tuberculosis. In: Barry 3rd CE, editor. Chemotherapy of tuberculosis. London: Butterworth; 1965. p. 175-91.

2. Grange J. Immunotherapy of tuberculosis. Tubercle 1970;71:237-9.

3. Venkataprasad $N$, Ledger $P$, Ivanyi J. The effect of glucosaminylmuramyl dipeptide injection to mice on the course of tuberculous infection and in vitro superoxide anion production. Int Arch Allergy Immunol 1997;114:23-9.

4. Johnson JL, Ssekasanvu E, Okwera A, Mayanja H, Hirsch CS, Nakibali JG, et al. Randomized trial of adjunctive interleukin-2 in adults with pulmonary tuberculosis. Am J Respir Crit Care Med 2003;168:185-91.

5. Mwinga A, Nunn A, Ngwira B, Chintu C, Warndorff D, Fine P, et al. Mycobacterium vaccae (SRL172) immunotherapy as an adjunct to standard antituberculosis treatment in HIV-infected adults with pulmonary tuberculosis: a randomised placebo-controlled trial. Lancet 2002;360:1050-5.

6. Lowrie DB, Silva CL. Enhancement of immunocompetence in tuberculosis by DNA vaccination. Vaccine 2000;18:1712-6.

7. Lowrie DB, Tascon RE, Bonato VL, Lima VM, Faccioli LH, Stavropoulos E, Colston MJ, Hewinson RG, Moelling K, Silva CL. Therapy of tuberculosis in mice by DNA vaccination. Nature 1999;400:269-71.
8. Ha SJ, Jeon BY, Kim SC, Kim DJ, Song MK, Sung YC, et al. Therapeutic effect of DNA vaccines combined with chemotherapy in a latent infection model after aerosol infection of mice with Mycobacterium tuberculosis. Gene Ther 2003;10:1592-9.

9. Cardona PJ, Amat I, Gordillo S, Arcos V, Guirado E, Diaz J, et al. Immunotherapy with fragmented Mycobacterium tuberculosis cells increases the effectiveness of chemotherapy against a chronical infection in a murine model of tuberculosis. Vaccine 2005;23:1393-8.

10. Turner J, Rhoades ER, Keen M, Belisle JT, Frank AA, Orme IM. Effective preexposure tuberculosis vaccines fail to protect when they are given in an immunotherapeutic mode. Infect Immun 2000;68:1706-9.

11. Repique CJ, Li A, Collins FM, Morris SL. DNA immunization in a mouse model of latent tuberculosis: effect of DNA vaccination on reactivation of disease and on reinfection with a secondary challenge. Infect Immun 2002;70:3318-23.

12. Guirado E, Amat I, Gil O, Diaz J, Arcos V, Caceres N, et al. Passive serum therapy with polyclonal antibodies against Mycobacterium tuberculosis protects against post-chemotherapy relapse of tuberculosis infection in SCID mice. Microbes Infect 2006;8:1252-9.

13. Barnes PF. Immunotherapy for tuberculosis: wave of the future or tilting at windmills? Am J Respir Crit Care Med 2003;168:142-3.

14. Who E. Report of the expert consultation on immunotherapeutic interventions for tuberculosis. Geneva: TRD/WHO; 2007.

15. Reljic R, Williams A, Ivanyi J. Mucosal immunotherapy of tuberculosis: is there a value in passive IgA? Tuberculosis (Edinburgh) 2006;86:179-90.

16. Buccheri S, Reljic R, Caccamo N, Ivanyi J, Singh M, Salerno A, et al. IL-4 depletion enhances host resistance and passive $\operatorname{IgA}$ protection against tuberculosis infection in BALB/c mice. Eur J Immunol 2007;37:729-37.

17. Reljic R, Clark SO, Williams A, Falero-Diaz G, Singh M, Challacombe S, et al Intranasal IFNgamma extends passive IgA antibody protection of mice against Mycobacterium tuberculosis lung infection. Clin Exp Immunol 2006;143: 467-73.

18. Tjarnlund A, Rodriguez A, Cardona PJ, Guirado E, Ivanyi J, Singh M, et al. Polymeric IgR knockout mice are more susceptible to mycobacterial infections in the respiratory tract than wild-type mice. Int Immunol 2006;18:807-16.

19. Medina E, North RJ. Resistance ranking of some common inbred mouse strains to Mycobacterium tuberculosis and relationship to major histocompatibility complex haplotype and Nramp1 genotype. Immunology 1998;93:270-4.

20. Cox JH, Ivanyi J. The role of host factors for the chemotherapy of BCG infection in inbred strains of mice. Apmis 1988;96:927-32.

21. Cox JH, Knight BC, Ivanyi J. Mechanisms of recrudescence of Mycobacterium bovis BCG infection in mice. Infect Immun 1989:57:1719-24.

22. Roach DR, Bean AG, Demangel C, France MP, Briscoe H, Britton WJ. TNF regulates chemokine induction essential for cell recruitment, granuloma formation and clearance of mycobacterial infection. J Immunol 2002;168:4620-7.

23. Saukkonen JJ, Bazydlo B, Thomas M, Strieter RM, Keane J, Kornfeld H. Betachemokines are induced by Mycobacterium tuberculosis and inhibit its growth. Infect Immun 2002;70:1684-93.

24. Wallis RS. Reconsidering adjuvant immunotherapy for tuberculosis. Clin Infect Dis 2005;41:201-8.

25. Yuan Y, Crane DD, Barry 3rd CE. Stationary phase-associated protein expression in Mycobacterium tuberculosis: function of the mycobacterial alpha-crystallin homolog. J Bacteriol 1996;178:4484-92.

26. Shi L, Jung YJ, Tyagi S, Gennaro ML, North RJ. Expression of Th1-mediated immunity in mouse lungs induces a Mycobacterium tuberculosis transcription pattern characteristic of nonreplicating persistence. Proc Natl Acad Sci U S A 2003;100:241-6.

27. Garbe TR, Hibler NS, Deretic V. Response to reactive nitrogen intermediates in Mycobacterium tuberculosis: induction of the 16-kilodalton alpha-crystallin homolog by exposure to nitric oxide donors. Infect Immun 1999;67: 460-5.

28. Sherman DR, Voskuil M, Schnappinger D, Liao R, Harrell MI, Schoolnik GK. Regulation of the Mycobacterium tuberculosis hypoxic response gene encoding alpha-crystallin. Proc Natl Acad Sci U S A 2001;98:7534-9.

29. Pheiffer C, Betts JC, Flynn HR, Lukey PT, van Helden P. Protein expression by a Beijing strain differs from that of another clinical isolate and Mycobacterium tuberculosis H37Rv. Microbiology (Reading, England) 2005;151:1139-50.

30. Abebe F, Bjune G. The emergence of Beijing family genotypes of Mycobacterium tuberculosis and low-level protection by bacille Calmette-Guerin (BCG) vaccines: is there a link? Clin Exp Immunol 2006;145:389-97.

31. Dieli F, Taniguchi M, Kronenberg M, Sidobre S, Ivanyi J, Fattorini L, et al. An antiinflammatory role for $\mathrm{V}$ alpha $14 \mathrm{NK} \mathrm{T}$ cells in Mycobacterium bovis bacillus Calmette-Guerin-infected mice. J Immunol 2003;171:1961-8.

32. Hernandez-Pando R, Aguilar D, Hernandez ML, Orozco H, Rook G. Pulmonary tuberculosis in BALB/c mice with non-functional IL-4 genes: changes in the inflammatory effects of TNF-alpha and in the regulation of fibrosis. Eur $J$ Immunol 2004;34:174-83. 